\title{
Reação de cultivares de algodoeiro a Rhizoctonia solani na fase de plântula e benefícios do tratamento de sementes com fungicidas
}

\author{
Augusto César Pereira Goulart
}

Embrapa Agropecuária Oeste - Caixa Postal 661 - CEP: 79804-970 Dourados, MS

Autor para Correspondência: Augusto César Pereira Goulart (augusto.goulart@embrapa.br)

Data de chegada: 28/08/2015. Aceito para publicação em: 19/07/2016.

$10.1590 / 0100-5405 / 2116$

\section{RESUMO}

Goulart, A.C.P. Reação de cultivares de algodoeiro a Rhizoctonia solani na fase de plântula e benefícios do tratamento de sementes com fungicidas. Summa Phytopathologica, v.42, n.4, p.308-312, 2016.

O objetivo desse trabalho foi avaliar a reação de onze genótipos de algodoeiro ao fungo Rhizoctonia solani AG-4, na fase de plântula, com potencial de uso em futuros programas de melhoramento bem como os benefícios do tratamento de sementes com fungicidas para cada cultivar em estudo. $\mathrm{O}$ experimento foi conduzido por dois anos nas casas de vegetação da Embrapa Agropecuária Oeste, em Dourados, MS. Sementes de cada cultivar, não tratadas e tratadas com a mistura fungicida tolylfluanid + pencycuron + triadimenol $(30+50+50 \mathrm{~g}$ do i.a./100kg de sementes), foram semeadas em areia contida em bandejas plásticas, dispostas em orifícios individuais, eqüidistantes e a $3 \mathrm{~cm}$ de profundidade. A inoculação com $R$. solani foi feita pela distribuição homogênea do inóculo do fungo na superfície do substrato (2,5g do inóculo do fungo/bandeja plástica com

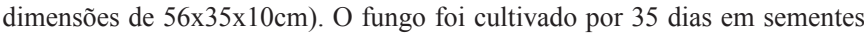
de aveia preta autoclavadas e trituradas em moinho $(1 \mathrm{~mm})$. As avaliações foram realizadas com base no desenvolvimento de sintomas e sobrevivência das plântulas, utilizando os dados de emergência inicial e final, tombamento de pós-emergência e plântulas lesionadas pelo patógeno. Foi observado efeito significativo da interação cultivares $x$ tratamento com fungicidas $(\mathrm{P}<0,05)$. Ficou claramente demonstrada a importância do tratamento das sementes de algodoeiro com fungicidas, sendo que as melhores emergências e os menores índices de doença (tombamento e plântulas lesionadas), independente da cultivar testada, foram obtidos quando as sementes foram tratadas. Em relação as cultivares avaliadas na ausência do tratamento da sementes com fungicidas, observou-se comportamento diferenciado de alguns genótipos com relação ao ataque do fungo $R$. solani, merecendo destaque BRS Aroeira, seguidas de BRS Cedro, BRS Ipê e FMT 701, demonstrando uma maior tolerância destas cultivares ao ataque de $R$. solani em comparação às demais. Enfatiza-se que a resistência, sozinha, não é suficiente para proporcionar efetivo controle desse patógeno. Porém, pode ser útil se integrada a outras estratégias complementares de controle, como o tratamento de sementes com fungicidas, reforçando o conceito de manejo integrado de doenças.

Palavras-chave: Gossypium hirsutum, tombamento, emergência, plântulas lesionadas.

\section{ABSTRACT}

Goulart, A.C.P. Reaction of cotton cultivars to Rhizoctonia solani at seedling stage and benefits of fungicide seed treatment. Summa Phytopathologica, v.42, n.4, p.308-312, 2016.

The aim of this study was to evaluate the reaction of eleven cotton genotypes to the fungus Rhizoctonia solani AG-4, at seedling stage, with potential for use in future genetic breeding programs, as well as the benefits of cotton seed treatment with fungicides for each tested cultivar. This experiment was carried out during two years at Embrapa Western Agriculture, in Dourados, Mato Grosso do Sul State, Brazil, under greenhouse conditions. Seeds of each cultivar, treated and untreated with the fungicide mixture tolylfluanid + pencycuron + triadimenol $(30+50+50 \mathrm{~g}$ a.i. $/ 100 \mathrm{~kg}$ of seeds), were sown in sand contained in plastic trays, by placing in equidistant 3 -cm-deep wells. Inoculation with $R$. solani was done by the homogeneous distribution of the fungus inoculum onto the substrate surface ( $2.5 \mathrm{~g}$ of the fungus inoculum/plastic tray of $56 \times 35 \times 10 \mathrm{~cm})$. The fungus was grown for 35 days on autoclaved black oat seeds and then ground to powder by using a mill $(1 \mathrm{~mm})$. The evaluations were done based on symptom development and seedling survival, using initial and final data on emergence, post-emergence damping-off and seedlings lesioned by the pathogen. Significant effect of the interaction cultivars $\mathrm{x}$ fungicide treatment was observed $(\mathrm{P}<0.05)$. The importance of cotton seed treatment with fungicides was clearly demonstrated, and the best results in relation to emergence and disease level (damping-off and lesioned seedlings), regardless of the tested cultivar, were obtained when the seeds were treated. In the absence of seed treatment with fungicides, different behaviors among cultivars in relation to the attack of $R$. solani were observed, being distinct in BRS Aroeira, followed by BRS Cedro, BRS Ipê and FMT 701, which showed higher tolerance to $R$. solani. It is emphasized that resistance alone is not sufficient for proper control of this pathogen. However, it may be useful if integrated with other complementary control strategies, including seed treatment with fungicides, strengthening the concept of integrated disease management.

Keywords: Gossypium hirsutum, damping-off, emergence, lesioned seedlings.

Com o incremento da área de plantio do algodoeiro (Gossypium hirsutum L.) no Brasil associado ao uso de cultivares mais suscetíveis, tem-se observado um aumento significativo dos problemas fitossanitários, principalmente aqueles relacionados à ocorrência de doenças na fase inicial de desenvolvimento da cultura conforme Goulart (13). Dentre elas, o "tombamento" é considerado uma das principais de acordo com relatos de Davis et al. (4), Wang \& Davis (30) e Goulart
(9). Nas condições do Brasil, principalmente em se tratando do algodão do cerrado, o principal agente causal do tombamento de plântulas é Rhizoctonia solani Kuhn grupo de anastomose (AG)-4 (teleomorfo: Thanatephorus cucumeris (A.B. Frank) Donk), pela freqüência que ocorre (mais de $95 \%$ dos casos) e pelos danos que causa na fase inicial de estabelecimento da lavoura, segundo Goulart $(9,10)$. Este fungo ataca as sementes e plântulas de algodão, causando o tombamento em 
pré e pós emergência $(11,12,23)$. De acordo com relatos de Chitarra et al. (3) e Goulart (14) este patógeno, estando presente no solo, além de ocasionar perdas significativas na fase de plântulas com consequente redução de stand, poderá servir como fonte de inóculo para culturas subsequentes.

Segundo Zambolim et al. (33) o controle do tombamento de plântulas do algodoeiro poderá ser obtido através do desenvolvimento de um sistema de Manejo Integrado, o qual baseia-se no princípio de manter a doença abaixo do limiar de dano econômico, utilizando medidas biológicas, culturais e químicas.

Nesse contexto, o tratamento de sementes com fungicidas eficientes tem sido a medida mais empregada e eficiente para o controle de $R$. solani, sendo considerado uma ferramenta estratégica dentro do contexto do manejo integrado de doenças, conforme evidenciam Garber et al. (7), Davis et al. (4), Wang \& Davis (30), Goulart (11, 12, 13). Entretanto, existe uma lacuna a ser preenchida quando se considera o portfólio de produtos recomendados para o tratamento de sementes de algodoeiro, havendo a necessidade premente de novas moléculas mais específicas visando o controle das doenças causadas por esse patógeno (quer seja em relação ao tombamento de plântulas quanto á mela). Resultados de pesquisa têm demonstrado que as misturas que têm em suas formulações fungicidas à base de estrobilurinas e de carboxamidas são as mais eficazes no controle desse patógeno. Como exemplo de fungicidas pertencentes a esses grupos podemos citar algumas estrobilurinas que apresentam estas características, como, por exemplo, a piraclostrobina e a azoxistrobina, e o sedaxane, do grupo das carboxamidas. Dessa forma, a ação combinada de fungicidas sistêmicos com protetores tem sido uma estratégia das mais eficazes no controle do tombamento de plântulas, causado por $R$. solani, uma vez que o espectro de ação da mistura é ampliado pela ação de dois ou mais produtos.

Considerando todas as táticas de controle dentro do manejo integrado de doenças, a resistência genética é o método mais eficiente e econômico. Entretanto, em se tratando do algodoeiro e mais especificamente em relação ao tombamento de plântulas causado por $R$. solani, poucas evidências científicas foram encontradas no sentido de afirmar que a resistência genética à esse patógeno existe. De acordo com Mathre \& Otta (22) e Stanton et al. (27), vários germoplasmas de algodoeiro têm sido testados para resistência à $R$. solani. Entretanto, segundo relatos de Thaxton et al. (28), fontes altamente resistentes não tem sido identificadas, com os resultados mostrando apenas genótipos tolerantes. Apenas um trabalho no Brasil desenvolvido por Goulart (12) mostrou o comportamento de algumas cultivares de algodoeiro disponíveis no mercado frente a ação desse patógeno. Nos Estados Unidos da América, trabalhos semelhantes foram desenvolvidos por Hefner (16), Bush et al. (2) e Garber et al. (7) mostraram diferentes respostas de cultivares de algodoeiro frente ao patógeno $R$. solani. Segundo Poswal et al., (25) a resistência de plântulas de algodoeiro a $R$. solani é do tipo poligênica com baixa herdabilidade.

Trabalhos de pesquisa realizados em casa de vegetação, visando determinar o desempenho de fungicidas aplicados em tratamento de sementes de algodão, tem sido um indicador bastante útil para predizer a eficácia desses produtos em nível de campo, conforme resultados obtidos por DeVay et al. (5), Goulart $(11,14,15)$ e Chitarra et al. (3). Esta mesma consideração é válida para estudos visando determinar a suscetibilidade de cultivares de algodoeiro a $R$. solani, segundo relatos de Bush et al. (2), Garber et al. (8), Hefner (16), Wang \& Davis (30) e Goulart (12). Nesse contexto, Parlevliet (24) evidencia que apesar das avaliações mais reais dos componentes da resistência ao patógeno devessem ser desenvolvidas em nível de campo, experimentos em casa de vegetação podem oferecer uma ideia do comportamento do material, predizendo-se genótipos potencialmente melhores. A viabilidade da utilização dessa metodologia vem sendo confirmada ao longo dos anos com a realização de inúmeros trabalhos, com resultados altamente confiáveis.

O objetivo desse trabalho foi avaliar a reação de algumas cultivares de algodoeiro à $R$. solani, na fase de plântula, com potencial de uso em futuros programas de melhoramento e os benefícios do tratamento de sementes com fungicidas para cada cultivar em estudo.

\section{MATERIAL E MÉTODOS}

Os ensaios foram conduzidos em condições de casa de vegetação, na Embrapa Agropecuária Oeste, em Dourados, MS, sendo repetidos por dois anos. O inóculo do patógeno foi composto de sementes de aveia preta colonizada por $R$. solani AG-4, isolado de lesões do coleto de plântulas de algodoeiro. Culturas puras do patógeno foram mantidas em meio de cultura BDA por 48 horas. Após esse período, o fungo foi repicado para um substrato composto de $2 \mathrm{~kg}$ de sementes de aveia preta e $1 / 2$ litro de água, previamente autoclavado, durante 30 minutos, por três dias consecutivos, a $127^{\circ} \mathrm{C}(1,5 \mathrm{~atm}$ de pressão), sendo mantido em condições ambientes por 35 dias. Após este período a aveia colonizada pelo fungo foi seca à sombra por dez dias, triturada em um moinho (1mm), de modo a se obter o inóculo do patógeno, na forma de um pó. O substrato utilizado para a semeadura foi areia lavada, previamente autoclavada (por três vezes consecutivas), sendo cada uma por 3 horas a $127^{\circ} \mathrm{C}(1,5 \mathrm{~atm}$ de pressão), contida em bandejas plásticas $(56 \times 35 \times 10 \mathrm{~cm})$.

Sementes de algodoeiro, deslintadas com ácido sulfúrico, das diferentes cultivares testadas (BRS Aroeira, BRS Ipê, BRS Araçá, BRS Cedro, BRS 269-Buriti, Nuopal, Fibermax 966, Fibermax 910, FMT 501, FMT 701 e Algodão 2043), tratadas e não tratadas com os fungicidas, foram semeadas em orifícios individuais, eqüidistantes e a $3 \mathrm{~cm}$ de profundidade e avaliadas quanto à suscetibilidade a $R$. solani AG-4. Antes do fechamento dos orifícios, foi feita a inoculação com $R$. solani. Uma quantidade pré estabelecida do inóculo do patógeno foi misturada em $1 \mathrm{~kg}$ de areia, sendo esta mistura distribuída homogeneamente na superfície do substrato, de modo a cobrir todas as sementes, ficando em contato direto com as mesmas. Foi definida uma densidade populacional do fungo (2,5g do inóculo do fungo/bandeja), com base na patogenicidade do inóculo inicial de $R$. solani, nível este ajustado em função da percentagem de tombamento observado, de modo que o mesmo proporcione, no máximo, $50 \%$ de tombamento, conforme metodologia proposta por Weinhold (31) e Wang \& Davis (30).

Para as avaliações de emergência inicial e final, de tombamento de pós-emergência e de plântulas lesionadas pelo patógeno, foi utilizado o "growing on test", com base no desenvolvimento de sintomas e sobrevivência das plântulas. Foram semeadas 200 sementes em cada bandeja plástica, sendo realizadas duas avaliações de emergência: a avaliação inicial (aos sete dias após a semeadura - 7 DAS) e a avaliação final (aos 26 DAS). A avaliação de tombamento foi realizada diariamente, a partir dos 7 DAS, computando-se o número de plântulas tombadas até os 26 DAS. Ao final dos 26 DAS, as plântulas remanescentes foram coletadas e avaliadas quanto à presença de sintomas do patógeno. Foram consideradas infectadas aquelas com sintomas típicos de tombamento (lesões deprimidas, marrom avermelhadas, no colo e nas raízes das plântulas). Para a confirmação do patógeno, essas plântulas com sintomas de "tombamento" foram coletadas e submetidas a uma "câmara úmida". Após cinco dias de 
incubação, foi realizada a leitura e identificação do patógeno, com o auxílio de lupa binocular com iluminador de fibra ótica.

Os benefícios do tratamento de sementes de algodão com fungicidas para cada uma das onze cultivares testadas, também foi avaliado. Para tal, outras 200 sementes de cada cultivar foram tratadas com a mistura fungicida triadimenol+pencycuron+tolylfluanid $(50+50+30 \mathrm{~g}$ do i.a./100kg de sementes) e semeadas nas mesmas condições descritas anteriormente. $\mathrm{O}$ tratamento fungicida, quando necessário, foi realizado colocando-se os produtos sobre $500 \mathrm{~g}$ de sementes em sacos plásticos de 2,0 L e agitando-se o recipiente por alguns minutos até a completa cobertura das sementes pelos fungicidas.

Para garantir que os resultados revelem única e exclusivamente o efeito do fungo $R$. solani, foram utilizadas sementes livres de qualquer espécie de fungo (escolha baseada em resultados de vários testes de sanidade de sementes) que possa interferir nas avaliações.

O delineamento experimental utilizado foi o inteiramente casualizado, com quatro repetições de 200 sementes, perfazendo um total de 800 sementes/tratamento, em arranjo fatorial 2 (algodão com e sem tratamento) x 11 (cultivares de algodoeiro). Os dados de percentagem foram transformados para arc sen $\mathrm{x} / 100$ e submetidos à análise de variância. As médias foram comparadas pelo teste de Scott Knott, ao nível de $5 \%$ de probabilidade, com o ASSISTAT. Foi realizada análise conjunta dos dados experimentais obtidos nos dois anos de condução dos ensaios, tornando possível a comparação das médias dos tratamentos pertencentes a experimentos diferentes com mais precisão.

Para cada cultivar, foi deixada uma testemunha sem inoculação, para fins comparativos.

\section{RESULTADOS E DISCUSSÃO}

Nas Tabelas 1 a 4 encontram-se os resultados obtidos no trabalho, com relação à avaliação em casa de vegetação da reação de cultivares de algodoeiro a $R$. solani e benefícios do tratamento de sementes com fungicidas. Foi observado efeito significativo da interação cultivares $\mathrm{x}$ tratamento com fungicidas $(\mathrm{P}<0,05)$. Os resultados mostraram claramente a importância do tratamento das sementes de algodão com fungicidas, em relação à emergência inicial e final de plântulas de algodoeiro (Tabelas 1 e 2), bem como no tombamento de pósemergência e na percentagem de plântulas com sintomas desta doença (Tabelas 3 e 4). As melhores emergências e os menores índices de doença (tombamento e plântulas lesionadas), independente da cultivar testada, foram obtidos quando as sementes foram tratadas com a mistura tolylfluanid + pencycuron + triadimenol, em comparação aos resultados obtidos quando as sementes não foram tratadas. Esses resultados estão de acordo com aqueles obtidos por Goulart $(14,15)$ e Chitarra et al. (3), os quais demonstraram a eficácia do tratamento de sementes com fungicidas no controle do tombamento de plântulas de algodoeiro causado por $R$. solani.

No presente estudo foram observadas diferentes respostas das cultivares testadas frente ao patógeno $R$. solani (Tabelas 3 e 4). Observou-se um comportamento diferenciado de alguns materiais com relação ao ataque do fungo $R$. solani, merecendo destaque os genótipos BRS Aroeira, seguidas de BRS Cedro, BRS Ipê e FMT 701. Estas cultivares diferiram significativamente das demais testadas, apresentando menor incidência de tombamento e menor percentagem de plântulas com sintomas desta doença, demonstrando uma maior tolerância ao ataque de $R$. solani em comparação às demais, que apresentaram uma maior suscetibilidade ao patógeno. Resultados semelhantes foram obtidos anteriormente por Goulart (12), onde as
Tabela 1. Efeito de cultivares e do tratamento de sementes com fungicidas na emergência inicial de algodoeiro, em substrato inoculado com R. solani.

\begin{tabular}{lcc}
\hline & \multicolumn{2}{c}{ Emergência Inicial (\%) } \\
\hline Cultivares & Sementes tratadas & Sementes não tratadas \\
\hline BRS Aroeira & $88,0 \mathrm{~d} \mathrm{~A}$ & $81,5 \mathrm{~b} \mathrm{~B}$ \\
BRS Ipê & $88,5 \mathrm{~d} \mathrm{~A}$ & $79,5 \mathrm{~b} \mathrm{~B}$ \\
BRS Araçá & $96,0 \mathrm{~b} \mathrm{~A}$ & $65,5 \mathrm{~d} \mathrm{~B}$ \\
BRS Cedro & $92,0 \mathrm{c} \mathrm{A}$ & $86,5 \mathrm{a} \mathrm{B}$ \\
BRS 269 Buriti & $82,0 \mathrm{e} \mathrm{A}$ & $65,5 \mathrm{~d} \mathrm{~B}$ \\
Nuopal & $94,0 \mathrm{c} \mathrm{A}$ & $69,0 \mathrm{c} \mathrm{B}$ \\
FM 966 & $89,0 \mathrm{~d} \mathrm{~A}$ & $79,5 \mathrm{~b} \mathrm{~B}$ \\
FM 910 & $98,5 \mathrm{a} \mathrm{A}$ & $79,5 \mathrm{~b} \mathrm{~B}$ \\
FMT 501 & $87,0 \mathrm{~d} \mathrm{~A}$ & $70,5 \mathrm{c} \mathrm{B}$ \\
FMT 701 & $87,5 \mathrm{~d} \mathrm{~A}$ & $79,0 \mathrm{~b} \mathrm{~B}$ \\
CNPA GO 2043 & $85,0 \mathrm{e} \mathrm{A}$ & $77,5 \mathrm{~b} \mathrm{~B}$ \\
\hline Média & 89,99 & 75,78 \\
\hline C.V. (\%) & 2,96 & 3,48 \\
\hline
\end{tabular}

Médias seguidas pela mesma letra minúscula nas colunas não diferem entre si pelo teste de Scott Knott a 5\% e mesma letra maiúscula nas linhas não diferem entre si pelo teste de t a $5 \%$.

Tabela 2. Efeito de cultivares e do tratamento de sementes com fungicidas na emergência final de algodoeiro, em substrato inoculado com R. solani.

\begin{tabular}{lcc}
\hline & \multicolumn{2}{c}{ Emergência final (\%) } \\
\hline Cultivares & Sementes tratadas & Sementes não tratadas \\
\hline BRS Aroeira & $83,0 \mathrm{c} \mathrm{A}$ & $71,0 \mathrm{a} \mathrm{B}$ \\
BRS Ipê & $85,0 \mathrm{c} \mathrm{A}$ & $65,0 \mathrm{~b} \mathrm{~B}$ \\
BRS Araçá & $94,5 \mathrm{a} \mathrm{A}$ & $41,5 \mathrm{f} \mathrm{B}$ \\
BRS Cedro & $88,0 \mathrm{~b} \mathrm{~A}$ & $72,0 \mathrm{a} \mathrm{B}$ \\
BRS 269 Buriti & $76,0 \mathrm{~d} \mathrm{~A}$ & $34,5 \mathrm{~g} \mathrm{~B}$ \\
Nuopal & $89,5 \mathrm{~b} \mathrm{~A}$ & $44,0 \mathrm{f} \mathrm{B}$ \\
FM 966 & $88,0 \mathrm{~b} \mathrm{~A}$ & $48,0 \mathrm{e} \mathrm{B}$ \\
FM 910 & $95,5 \mathrm{a} \mathrm{A}$ & $57,0 \mathrm{c} \mathrm{B}$ \\
FMT 501 & $82,5 \mathrm{c} \mathrm{A}$ & $37,5 \mathrm{~g} \mathrm{~B}$ \\
FMT 701 & $85,5 \mathrm{c} \mathrm{A}$ & $65,0 \mathrm{~b} \mathrm{~B}$ \\
CNPA GO 2043 & $82,0 \mathrm{c} \mathrm{A}$ & $53,0 \mathrm{~d} \mathrm{~B}$ \\
\hline Média & 86,31 & 53,50 \\
\hline C.V. (\%) & 3,12 & 3,43 \\
\hline Médias seguidas pela mesma letra minúscula nas colunas não diferem entre si pelo teste de
\end{tabular}

Médias seguidas pela mesma letra minúscula nas colunas não diferem entre si pelo teste de

Scott Knott a 5\% e mesma letra maiúscula nas linhas não diferem entre si pelo teste de t a 5\%

Tabela 3. Efeito de cultivares e do tratamento de sementes com fungicidas no tombamento de pós emergência de plântulas de algodoeiro, em substrato inoculado com $R$. solani.

\begin{tabular}{lcc}
\hline & \multicolumn{2}{c}{ Tombamento (\%) } \\
\hline Cultivares & Sementes tratadas & Sementes não tratadas \\
\hline BRS Aroeira & 0,8 e B & 13,0 e A \\
BRS Ipê & 1,2 e B & $18,2 \mathrm{~d} \mathrm{~A}$ \\
BRS Araća & $5,0 \mathrm{~b} \mathrm{~B}$ & $36,2 \mathrm{~b} \mathrm{~A}$ \\
BRS Cedro & $3,4 \mathrm{~d} \mathrm{~B}$ & $16,7 \mathrm{~d} \mathrm{~A}$ \\
BRS 269 Buriti & $5,9 \mathrm{a} \mathrm{B}$ & $45,0 \mathrm{a} \mathrm{A}$ \\
Nuopal & $5,2 \mathrm{~b} \mathrm{~B}$ & $35,4 \mathrm{~b} \mathrm{~A}$ \\
FM 966 & $5,8 \mathrm{a} \mathrm{B}$ & $39,6 \mathrm{a} \mathrm{A}$ \\
FM 910 & $4,7 \mathrm{c} \mathrm{B}$ & $28,2 \mathrm{c} \mathrm{A}$ \\
FMT 501 & $4,9 \mathrm{c} \mathrm{B}$ & $46,6 \mathrm{a} \mathrm{A}$ \\
FMT 701 & $3,6 \mathrm{~d} \mathrm{~B}$ & $19,1 \mathrm{~d} \mathrm{~A}$ \\
CNPA GO 2043 & $4,8 \mathrm{c} \mathrm{B}$ & $31,4 \mathrm{c} \mathrm{A}$ \\
\hline Média & 4,14 & 30,00 \\
\hline C.V. (\%) & 6,36 & 6,92
\end{tabular}

Médias seguidas pela mesma letra minúscula nas colunas não diferem entre si pelo teste de Scott Knott a 5\% e mesma letra maiúscula nas linhas não diferem entre si pelo teste de t a $5 \%$. 
Tabela 4. Efeito de cultivares e do tratamento de sementes com fungicidas na percentagem de plântulas de algodoeiro com sintomas de $R$. solani no hipocótilo, em substrato inoculado com $R$. solani.

\begin{tabular}{lcc}
\hline & \multicolumn{2}{c}{ Plântulas com sintomas (\%) } \\
\hline Cultivares & Sementes tratadas & Sementes não tratadas \\
\hline BRS Aroeira & 3,3 e B & $14,4 \mathrm{f} \mathrm{A}$ \\
BRS Ipê & $4,0 \mathrm{~d} \mathrm{~B}$ & $15,8 \mathrm{f} \mathrm{A}$ \\
BRS Araçá & $7,4 \mathrm{a} \mathrm{B}$ & $82,5 \mathrm{a} \mathrm{A}$ \\
BRS Cedro & $5,1 \mathrm{c} \mathrm{B}$ & $25,7 \mathrm{e} \mathrm{A}$ \\
BRS 269 Buriti & 7,6 a B & $68,2 \mathrm{c} \mathrm{A}$ \\
Nuopal & $5,6 \mathrm{c} \mathrm{B}$ & $78,0 \mathrm{~b} \mathrm{~A}$ \\
FM 966 & $5,1 \mathrm{c} \mathrm{B}$ & $32,6 \mathrm{~d} \mathrm{~A}$ \\
FM 910 & $7,0 \mathrm{a} \mathrm{B}$ & $35,6 \mathrm{~d} \mathrm{~A}$ \\
FMT 501 & $6,7 \mathrm{~b} \mathrm{~B}$ & $68,2 \mathrm{c} \mathrm{A}$ \\
FMT 701 & $3,2 \mathrm{e} \mathrm{B}$ & $26,4 \mathrm{e} \mathrm{A}$ \\
CNPA GO 2043 & $6,6 \mathrm{~b} \mathrm{~B}$ & $39,8 \mathrm{~d} \mathrm{~A}$ \\
\hline Média & 5,50 & 44,30 \\
\hline C.V. (\%) & 7,83 & 6,92 \\
\hline
\end{tabular}

Médias seguidas pela mesma letra minúscula nas colunas não diferem entre si pelo teste de Scott Knott a 5\% e mesma letra maiúscula nas linhas não diferem entre si pelo teste de t a $5 \%$.

cultivares CNPA ITA 90 II E BRS Aroeira, BRS Cedro e BRS Ipê apresentaram-se como as mais resistentes a $R$. solani, apesar das diferenças de performance destas cultivares terem sido geralmente pequenas, o que também foi observado por Wang \& Davis (30), Bush et al. (2), Garber et al. (8), Hefner (16) e Wang \& Davis (30). Os resultados obtidos nesse trabalho mostraram a dificuldade de se obter fontes com alto nível de resistência a $R$. solani dentre os genótipos testados, apesar do comportamento diferenciado de alguns deles. Assunção et al. (1) obtiveram resultados semelhantes trabalhando com o patossistema fava (Phaseolus lunatus) x $R$. solani, onde dos 72 genótipos de fava testados, nenhum deles apresentou reação similar a imunidade sendo que somente quatro foram considerados como altamente resistentes. A maioria dos genótipos foram moderadamente resistentes $(72,2 \%)$, enquanto $18,1 \%$ foi suscetível e $4,2 \%$ altamente suscetível. Segundo Weinhold \& Sinclair (32), isso pode estar relacionado à elevada agressividade do agente patogênico ao hospedeiro devido a mecanismos de infecção não específicos.

Considerando a dificuldade de comprovação da existência da resistência genética do algodoeiro em relação à $R$. solani, com poucas evidências científicas sendo reportadas até o momento, outras linhas de pesquisa vem sendo exploradas no sentido de buscar uma explicação para a diferença de comportamento de certos materiais frente à esse patógeno. Segundo Rothrock (26), a resistência de plântulas de algodoeiro aumenta com a idade. Considerando essa hipótese, resultados obtidos por Hunter (17) e Hunter et al. (18) demonstraram diferenças na suscetibilidade das plântulas a $R$. solani entre cinco e doze dias após a semeadura. Vários mecanismos tem sido sugeridos para explicar estas mudanças na resistência. Hunter \& Guinn (20) sugerem que as plântulas de algodoeiro tornam-se mais resistentes ao tombamento de $R$. solani com a idade, em função do aumento da espessura da cutícula. Todavia, trabalhos relacionados aos mecanismos de defesa do hospedeiro têm focado nos aspectos relacionados às defesas bioquímicas, como a presença em plântulas de algodoeiro de compostos terpenóides, onde, segundo Hunter et al. (18) e Mace et al. (21), sete diferentes aldeídos estão envolvidos no processo de defesa. Além desses compostos, catequinas como os principais componentes de polifenóis (19) além da atividade de peroxidases (29), estão envolvidos no processo de defesa das plântulas ao patógeno $R$. solani.

Segundo Freire \& Farias (6), atualmente, os programas de melhoramento do algodoeiro no Brasil tem procurado desenvolver variedades com melhor nível de resistência às principais doenças que atacam a parte aérea dessa cultura. Em se tratando do tombamento de plântulas de algodoeiro, causado por $R$. solani, vale salientar que pouco se sabe quanto às reações das cultivares disponíveis no mercado frente a ação desse patógeno. Neste tocante, genótipos testados que apresentaram bons níveis de tolerância/resistência poderão ser selecionados e utilizados em futuros programas de melhoramento. Dessa forma, ressalta-se a importância desse resultado efetivamente inovador, o qual evidenciou diferenças significativas de comportamento das cultivares testadas em relação ao ataque desse patógeno, indicando como opções de manejo do tombamento de plântulas de algodoeiro causado por $R$. solani, o uso de genótipos com melhor nível de resistência, como as cultivares BRS Aroeira, BRS Cedro, BRS Ipê e FMT 701. Até o momento, apenas um trabalho desenvolvido no Brasil por Goulart (12) tinha mostrado o comportamento de alguns materiais em relação à $R$. solani. Por outro lado, deve-se enfatizar que os resultados obtidos nesse trabalho, mostraram de forma muito clara que esses níveis de tolerância, sozinhos, são insuficientes para proporcionar efetivo controle do patógeno. Porém, podem ser úteis se integrados a outras estratégias complementares de controle, como o tratamento de sementes com a mistura fungicida triadimenol+pencycuron+tolylfluanid $(50+50+30 \mathrm{~g}$ do i.a./100kg de sementes), o que também foi demonstrado nesse trabalho, reforçando o conceito de manejo integrado de doenças. Demonstrou-se com esse trabalho que não se deve dispensar o tratamento das sementes de algodoeiro com fungicidas, apesar de algumas cultivares terem apresentado certa tolerância ao patógeno. Assim, sugere-se, em áreas com histórico de ocorrência de $R$. solani, dar preferência às cultivares que apresentarem melhor comportamento frente ao patógeno, visando otimizar a eficácia do fungicida aplicado às sementes de algodoeiro. Deve-se considerar ainda que a obtenção desses resultados poderá contribuir para um melhor entendimento da biologia de $R$. solani, incluindo as relações entre a doença e o comportamento de diferentes cultivares frente ao patógeno.

\section{REFERÊNCIAS}

1. Assunção, I.P.; Nascimento, L.D.; Ferreira, M.F.; Oliveira, F.J.; Michereff, S.J.; Lima, G.S.A. Reaction of faba bean genotypes to Rhizoctonia solani and resistance stability. Horticultura Brasileira, Brasília, DF, v.29, n. 4, p. 492-497. 2011.

2. Bush, D.L.; Bird, L.S.; Bourland, F.M. Variation in susceptibility to Rhizoctonia solani among MAR cotton cultivars. In: Beltwide Cotton Production Research Conferences, 1978. Proceedings. Memphis: National Cotton Council, 1978. p.21

3. Chitarra, L.G.; Goulart, A.C.P.; Zorato, M.F. Tratamento de sementes de algodoeiro com fungicidas no controle de patógenos causadores de tombamento de plântulas. Revista Brasileira de. Sementes, Londrina, v.31, n.1, p. 168-176, 2009.

4. Davis, R.M.; Nunez, J.J.; Subbarao, K.V. Benefits of cotton seed treatments for the control of seedling diseases in relation to inoculum densities of Pythium species and Rhizoctonia solani. Plant Disease, St. Paul, v.81, n.7, p.766-768, 1997.

5. Devay, J.E.; Garber, R.H.; Wakeman, R.J. Cotton seedling responses in greenhouse tests to combinations of chemical seed treatment for control of Pythium ultimum, Rhizoctonia solani, and Thielaviopsis basicola. In: Beltwide Cotton Production Research Conferences, 1980. Proceedings. Memphis: National Cotton Council, 1980. p.19.

6. Freire, E.C.; Farias, J.C.F. Cultivares de algodoeiro para o Centro-Oeste. In: Embrapa Agropecuária Oeste; Embrapa Algodão. Algodoeiro: tecnologia de produção. Dourados; Embrapa Agropecuária Oeste; Campina Grande: 
Embrapa Algodoeiro, 2001. p.159-180.

7. Garber, R.H.; Devay, J.E.; Weinhold; A.R.; Wakeman, R.J. Pathogen inoculum a key factor in fungicide seed treatment efficiency. In: Beltwide Cotton Production Research Conferences, 1980. Proceedings. Memphis: National Cotton Council, 1980. p.19.

8. Garber, R.H.; Devay, J.E.; Wakeman, R.J.; Vargas, L. The role of cultivar tolerance in cotton seedling disease control. In: Beltwide Cotton Conferences, 1991, San Antonio. Proceedings... Memphis: National Cotton Council, 1991. v.1, p.163-165. Disponível em: <http://www.cotton.org/ beltwide/proceedings $>$. Acesso em: 6 out. 2004.

9. Goulart, A.C.P. Tratamento de sementes do algodoeiro com fungicidas. In: Embrapa Agropecuária Oeste; Embrapa Algodão. Algodoeiro: tecnologia de produção. Dourados: Embrapa Agropecuária Oeste; Campina Grande: Embrapa Algodoeiro, 2001. p.140-158.

10. Goulart, A.C.P. Benefícios do tratamento de sementes de algodoeiro com fungicidas no controle do tombamento em relação à densidade de inóculo de Rhizoctonia solani. Fitopatologia Brasileira, Brasília, DF, v.27, p.218, 2002. Suplemento.

11. Goulart, A.C.P. Efeito do tratamento de sementes de algodoeiro com fungicidas no controle do tombamento em relação à densidade de inóculo de Rhizoctonia solani. Summa Phytopathologica, Botucatu, v.32, n.4, p. 360-366, 2006.

12. Goulart, A.C.P. Suscetibilidade de cultivares de algodoeiro a Rhizoctonia solani e benefícios do tratamento de sementes com fungicidas. Summa Phytopathologica, Botucatu, v.33, n.3, p. 222-228, 2007

13. Goulart, A.C.P. Manejo de doenças iniciais do algodoeiro. Tropical Plant Pathology, Lavras, v.33, p. 63-65, 2008. Suplemento.

14. Goulart, A.C.P. Controle do tombamento de plântulas de algodoeiro causado por Rhizoctonia solani pelo tratamento de sementes com fungicidas. Dourados: Embrapa Agropecuária Oeste. 2008a. 31p. (Boletim de Pesquisa e Desenvolvimento/Embrapa Agropecuária Oeste, ISSN 1679-0456; 45)

15. Goulart, A.C.P. Efeito do tratamento de sementes de algodoeiro com fungicidas no controle do tombamento de plântulas causado por Rhizoctonia solani, sob condições de casa de vegetação. Tropical. Plant Pathology, Lavras, , v.33, n.5, pp. 394-398, 2008 b.

16. Hefner, J.J. Screening cotton for resistance to damping-off by Rhizoctonia solani. In: Beltwide Cotton Production Research Conferences, 1968. Proceedings... Memphis: National Cotton Council, 1968. p.164-165.

17. Hunter, R.E. Inactivation of pectic enzymes by polyphenois in cotton seedlings of diferente ages infected with Rhizoctonia solani. Physiological Plant Pathology, London, v.4, p.151-159. 1974.

18. Hunter, R.E.; Halloin, J.M.; Veech, J.A.; Carter, W.W. Terpenoid accumulation in hypocotyls of cotton seedlings during aging and after infection by Rhizoctonia solani. Phytopathology, Saint Paul, v.68, p.347-350. 1978.

19. Hunter, R.E. Effects of catechin in culture and in cotton seedlings on the growth and polygalacturonase acivity of Rhizoctonia solani. Phytopathol- ogy, Saint Paul, v.68, p.1032-1036. 1978.

20. Hunter, R.E.; Guinn, G. Effect of root temperature on hypocotyls of cotton seedlings as a source of nutrition for Rhizoctonia solani. Phytopathology, Saint Paul, v.58, p.981-984. 1968.

21. Mace, M.E.; Bell, A.A.; Stipanovic, R.D. Histochemistry and isolation of gossypol and related terpenoids in roots of cotton seedlings. Phytopathology, Saint Paul, v.64, p.1297-1302. 1974.

22. Mathre, D.E.; Otta, J.D. Sources of resistance in the genus Gossypium to several soilborne pathogens. Plant Disease Reporter, Saint Paul, v.51, p.864-867. 1967.

23. Moustafa-Mahmoud, S.M.; Sumner, D.R.; Ragab, M.M.; Ragab, M.M. Interaction of fungicides, herbicides, and planting date with seedling disease of cotton caused by Rhizoctonia solani AG-4. Plant Disease, Saint Paul, v.77, p.79-86. 1993.

24. Parlevliet, J.E. Components of resistance that reduce the rate of epidemic development. Annual Review of Phytopathology, Palo Alto, v.17, p.203$222,1979$.

25. Poswal, M.A.T.; El-Zik, K.M.; Biro, L.S. Gene action and inheritance of resistance to Rhizoctonia solani and Pythium ultimum in cotton seedlings. Phytopathology, Saint Paul, v.76., p.1107. 1986.

26. Rothrock, C.S. Cotton diseases incited by Rhizoctonia solani. In: Sneh, B.; Jabaji-Hare, S.; Neate, S.; Dijst, G. Rhizoctonia species: taxonomy, molecular biology, ecology, pathology and disease control, Dordrecht, Netherlands, Kluwer Academic Publishers, 1996. v.3, p.269-277.

27. Stanton, M.A.; Rothrock, C.S.; Stewart, J.McD. Response of A. genome cotton germplasm to the seedling disease pathogens, Rhizoctonia solani and Pythium ultimum. Genetic Resources and Crop Evolution, Witzenhausen, Germany, v.41, p.9-12. 1994.

28. Thaxton, P.M.; El-Zik, K.M.; Kirkpatrick, R.K. Genetic gains in resistence to pests in the MAR germplasm. In: Herber, D.J.; Richter, D.A. (eds.). Proceedings of the cotton belt-wide producers research conference. Memphis: Cotton Council of America, 1991. p.151-156.

29. Veech, J.A. Localization of peroxidase in Rhizoctonia solani-infected cotton seedlings. Phytopathology, Saint Paul, v.66., p.1072-1076. 1976.

30. Wang, H.; Davis, R.M. Susceptibility of selected cotton cultivars to seedling disease pathogens and benefits of chemical seed treatments. Plant Disease, St. Paul, v.18, n.9, p.1085-1088, 1997.

31. Weinhold, A.R. Population of Rhizoctonia solani in agricultural soils determined by a screening procedure.Phytopathology, St. Paul, v.67, p.566-569, 1977.

32. Weinhold A.R; Sinclair J.B. Rhizoctonia solani: penetration, colonization, and host response. In: Sneh B.; Jabaji-Hare S.; Neate S.; Dijst G. (eds) Rhizoctonia species: taxonomy, molecular biology, ecology, pathology and disease control. Dordrecht: Kluwer Academic Publishers. p. 163-174. 1996.

33. Zambolim, L.; Casa, R.T.; Reis, E.M. Sistema plantio direto e doenças em plantas. Fitopatologia Brasileira, Brasília, DF, v.25, n.4, p.585-595. 2000. 